\title{
Suicide attempts and related factors in patients admitted to a general hospital: a ten-year cross- sectional study (1997-2007)
}

\author{
Jesús Alberdi-Sudupe ${ }^{1 *}$, Salvador Pita-Fernández², Sonia M Gómez-Pardiñas ${ }^{1}$, Fernando Iglesias-Gil-de-Bernabé', \\ Jorge García-Fernández ${ }^{1}$, Gonzalo Martínez-Sande ${ }^{1}$ Sara Lantes-Louzao ${ }^{1}$ and Sonia Pértega-Díaz ${ }^{2}$
}

\begin{abstract}
Background: Suicide and suicide attempts represent a severe problem for public health services. The aim of this study is to determine the socio-demographic and psychopathological variables associated with suicide attempts in the population admitted to a General Hospital.

Methods: An observational-descriptive study of patients admitted to the A Coruña University Hospital (Spain) during the period 1997-2007, assessed by the Consultation and Liaison Psychiatric Unit. We include $n=5,234$ admissions from 4,509 patients. Among these admissions, $\mathrm{n}=361(6.9 \%)$ were subsequent to a suicide attempt. Admissions arising from a suicide attempt were compared with admissions occurring due to other reasons. Multivariate generalised estimating equation logistic regression models were used to examine factors associated with suicide attempts.

Results: Adjusting by age, gender, educational level, cohabitation status, being employed or unemployed, the psychiatric diagnosis at the time of the interview and the information on previous suicide attempts, we found that the variables associated with the risk of a suicide attempt were: age, psychiatric diagnosis and previous suicide attempts.

The risk of suicide attempts decreases with age $(O R=0.969)$. Psychiatric diagnosis was associated with a higher risk of suicide attempts, with the highest risk being found for Mood or Affective Disorders (OR = 7.49), followed by Personality Disorders $(\mathrm{OR}=7.31)$, and Schizophrenia and Other Psychotic Disorders $(\mathrm{OR}=5.03)$.

The strongest single predictive factor for suicide attempts was a prior history of attempts $(O R=23.63)$.

Conclusions: Age, psychopathological diagnosis and previous suicide attempts are determinants of suicide attempts.
\end{abstract}

\section{Background}

Suicide attempts constitute a serious problem for public healthcare services [1-3]. The data published on suicide attempts in Spain are scant $[4,5]$, and no data are available on patients admitted to General Hospitals in our public healthcare setting after a suicide attempt.

Suicidal behaviour not only includes suicides, but also those suicide attempts which do not result in the patient's death. Mental phenomena, such as suicidal

\footnotetext{
* Correspondence: jesus.alberdi.sudupe@sergas.es

'Department of Psychiatry, A Coruña Hospital, UPIE Planta Baja, Hospital de Oza, As Xubias, 84, 15006 A Coruña, Spain

Full list of author information is available at the end of the article
}

impulses or unconsummated ideations can also be included, as well as a wide range of behaviours which are pernicious to the patient's health without a previous explicit declaration of a suicidal intention [6,7].

A variety of factors are associated with an increased risk of suicide and attempted suicide [8], including psychiatric disorders [9-14], feelings of hopelessness and impulsivity $[15,16]$, history of previous suicide attempts $[9,17,18]$, age, sex and race [19-24], marital status $[25,26]$, occupation [27], comorbidity [28,29], adverse childhood experiences [30], family history [31,32], and accessibility to weapons, especially firearms [33].



(c) 2011 Alberdi-Sudupe et al; licensee BioMed Central Ltd. This is an Open Access article distributed under the terms of the Creative Commons Attribution License (http://creativecommons.org/licenses/by/2.0), which permits unrestricted use, distribution, and reproduction in any medium, provided the original work is properly cited. 
A recent paper [34] highlights the similarities and differences among heterogeneous groups of patients, some of whom committed suicide, and others who survived the attempt. The authors conclude that depressive symptoms are present in both groups as a shared variable.

Some of the individuals who attempt to commit suicide (by physically inflicting self-harm or ingesting a product at toxic dose levels) are taken to the Emergency Departments of General Hospitals, while others remain in their family or social environment after the attempt, with no specific health care; no official statistics on attempted suicides are available.

A proportion of these attending Accident and Emergency Departments will be admitted to the General Hospital's Medical and Surgical Departments, owing to the surgical lesions and medical comorbidity present after the suicide attempt. In this paper, we study patients admitted to a General Hospital, serving a health area with a population of 500,000, who required hospital admission, and for whom psychiatric assessment by the Consultation and Liaison Psychiatric Unit was requested, over an 11-year period (1997-2007). The aim of the present study was to determine the variables associated to suicide attempts in this group of admissions.

\section{Methods}

\section{Setting and patients}

The patients successively admitted to the A Coruña hospital between 1997 and 2007, with the exception of those admitted to the Department of Psychiatry, who required attention from the Consultation and Liaison Psychiatric Unit at the request of the appropriate Medical or Surgical Unit.

\section{Design}

An observational-descriptive study of prevalence, using the hospital records of the patients attended. Admissions due to attempted suicide were compared with admissions for other reasons.

\section{Inclusion criteria}

Patients admitted to the hospital during the study period, and for whom psychiatric assessment by the Consultation and Liaison Psychiatric Unit was requested.

\section{Exclusion criteria}

Patients who were admitted directly to the Department of Psychiatry after assessment in the Emergency Department.

\section{Measures}

For every patient included in the study, the following variables were assessed: age, gender, marital and cohabitation status, educational level, referring hospital department, profession, occupational situation, psychiatric diagnosis with the psychiatric interview (in line with DSM-IV and ICD-10 criteria), medical and surgical risk at the time of the psychiatric assessment, psychiatric personal and family background, therapeutic intervention during hospital admission, including the prescribed pharmacological treatment and psychotherapy.

\section{Sample size justification}

The sample size ( $\mathrm{n}=5,234$ admissions) makes it possible for the parameters of interest to be estimated with a confidence of $95 \%(\alpha=0.05)$ and a precision of $\pm 1.35 \%$.

\section{Statistical analysis}

The quantitative variables are expressed as mean \pm standard deviation (SD); the qualitative variables are expressed as an absolute value (n) and the percentage, with the estimation of the $95 \%$ confidence interval (CI).

Comparisons for quantitative variables were made with the Student-T or Mann Whitney test, depending on which was appropriate subsequent to the verification of normality using the Kolgomorov-Smirnov test.

Qualitative variables associations were analysed using the Pearson Chi-Square test.

As some patients were admitted on multiple occasions, independent variables (i.e. demographic and clinical characteristics) may represent the same individual, giving rise to a lack of independence. In order to account for the correlated nature of these data, generalised estimating equations were used to assess associations between demographic and clinical characteristics and hospitalisation for suicide attempts [35]. Multivariate generalised estimating equation logistic regression models were used to examine factors associated with suicide attempts. The area under the ROC curve (AUC) was computed as a measure of model validity. All statistical analyses were performed using SPSS 17.0 and R 2.10.0, in addition to the Geepack package [36].

\section{Ethical-legal aspects}

Authorisation was requested from the Clinical-Research Ethics Committee (CEIC) and confidentiality was preserved in accordance with the current Spanish Data Protection Law (15/1999).

\section{Results}

\section{Descriptive study}

The population under study consists of patients admitted to the Medical and Surgical Departments of the Complexo Hospitalario Universitario A Coruña (CHUAC), assessed by the Consultation and Liaison Psychiatric Unit of the Department of Psychiatry.

The analysis was conducted with hospitalisation as the unit of analysis. We include $n=5,234$ admissions from 
4,509 patients. This means that 725 (16.1\%) were readmissions, some concerning the same patients.

Among the admissions occurring during the research period (1997 to 2007), $\mathrm{n}=361$ (6.9\%) were subsequent to a suicide attempt. $58.4 \%$ of the suicide attempts were committed by women. Patients admitted subsequent to a suicide attempt were younger than those admitted for other reasons $(42.5 \pm 17.8$ vs. $51.5 \pm 18.1$ years of age; $\mathrm{p}<0.001)$

The general features of the patients assessed, according to the presence or absence of suicide attempts, are shown in Table 1.

\section{Univariate analysis}

In the univariate analysis, the variables significantly associated with suicide attempts were: age, gender, marital and cohabitation status, employment status, educational level, the psychiatric diagnosis according to DSMIV-TR criteria (ICD-10 codes) and previous suicide attempts (Table 1).

Globally, the group of patients who attempted a suicide was significantly $(\mathrm{p}<0.05)$ younger than the group of patients who had not (42.5 years of age vs. 51.5 years of age). There was also a higher percentage of women in the suicide attempt group than in the non-suicide attempt group (58.4\% vs. $45.7 \%$ ).

With regard to marital status, the percentages of single $(40.4 \%$ vs. $28.0 \%)$ and separated individuals $(13.6 \%$ vs. $8.1 \%$ ) were also higher in the suicide attempt group than in the comparison group.

In relation to the cohabitation status variable, out of those patients who had made a suicide attempt, the percentage living with their parents $(22.5 \%$ vs. $13.9 \%)$ or other relatives $(15.3 \%$ vs. $9.7 \%)$ was higher than in the comparison group. The percentage of patients living with a partner and children was lower in the suicideattempt group than in the non-suicide attempt group (38.6\% vs. $52.6 \%)$.

The percentage of employment in the suicide attempt group is higher than in the other group of patients (49.6\% vs. $32.8 \%)$, and higher educational levels were found in those attempting suicide attempt than in the other group.

With regard to grouped diagnosis, in accordance with the DSM-IV-R categories formulated with ICD-10 codes, a higher prevalence of psychiatric disorders was found in the suicide attempt group (12.3\% vs. 5.7\% for Psychotic Disorders, $29.5 \%$ vs. $11.1 \%$ for Mood of Affective Disorders, $24.2 \%$ vs. $5.4 \%$ for Personality Disorders).

There was also a higher prevalence of previous suicide attempts in the suicide attempter group than in the comparison group (9.1\% vs. $0.1 \%)$.

In the univariate analysis, the variables not associated with the risk of attempted suicide were the province or domicile and the year of participation in the study.
Table 1 General features of the episodes attended according to presence or absence of suicide attempt

\begin{tabular}{|c|c|c|c|c|c|}
\hline & \multicolumn{2}{|c|}{$\begin{array}{l}\text { No suicide } \\
\text { attempt }\end{array}$} & \multicolumn{2}{|c|}{$\begin{array}{l}\text { Suicide } \\
\text { attempt }\end{array}$} & \multirow[b]{2}{*}{$p$} \\
\hline & Mean & SD & Mean & SD & \\
\hline \multirow[t]{2}{*}{ Age } & 51.5 & 18.1 & 42.5 & 17.8 & $<0.001$ \\
\hline & $n$ & $\%$ & $n$ & $\%$ & $p$ \\
\hline Gender & & & & & $<0.001$ \\
\hline Men & 2647 & 54.3 & 150 & 41.6 & \\
\hline Women & 2226 & 45.7 & 211 & 58.4 & \\
\hline Marital Status & & & & & $<0.001$ \\
\hline Single & 1356 & 28.0 & 146 & 40.4 & \\
\hline Married & 2529 & 52.3 & 138 & 38.2 & \\
\hline Separated & 394 & 8.1 & 49 & 13.6 & \\
\hline Widowed & 536 & 11.1 & 25 & 6.9 & \\
\hline Religious & 7 & 0.1 & 2 & 0.6 & \\
\hline Others & 18 & 0.4 & 1 & 0.3 & \\
\hline Cohabitation status & & & & & $<0.001$ \\
\hline Alone & 649 & 13.4 & 48 & 13.3 & \\
\hline Partner and children & 2556 & 52.6 & 139 & 38.6 & \\
\hline Parents & 673 & 13.9 & 81 & 22.5 & \\
\hline Alone with children & 330 & 6.8 & 22 & 6.1 & \\
\hline With other relatives & 472 & 9.7 & 55 & 15.3 & \\
\hline Institution & 90 & 1.9 & 7 & 1.9 & \\
\hline Others & 69 & 1.4 & 7 & 1.9 & \\
\hline Homeless & 18 & 0.4 & 1 & 0.3 & \\
\hline Employment & & & & & $<0.001$ \\
\hline No & 3249 & 67.2 & 181 & 50.4 & \\
\hline Yes & 1584 & 32.8 & 178 & 49.6 & \\
\hline Educational level & & & & & 0.013 \\
\hline No Education & 825 & 17.2 & 40 & 11.3 & \\
\hline $\begin{array}{l}\text { Primary and Secondary } \\
\text { Education }\end{array}$ & 3587 & 74.8 & 281 & 79.2 & \\
\hline $\begin{array}{l}\text { Higher and University } \\
\text { Education }\end{array}$ & 385 & 8.0 & 34 & 9.6 & \\
\hline $\begin{array}{l}\text { DSM-IV-TR grouped diagnosis } \\
\text { with } \\
\text { ICD-10 codes }\end{array}$ & & & & & $<0.001$ \\
\hline $\begin{array}{l}\text { Schizophrenia and other } \\
\text { Psychotic Disorders (333). F20- } \\
\text { F29 }\end{array}$ & 274 & 5.7 & 44 & 12.3 & \\
\hline $\begin{array}{l}\text { Mood or Affective Disorders } \\
\text { (387). F30-39 }\end{array}$ & 533 & 11.1 & 106 & 29.5 & \\
\hline Personality Disorders (765). F60 & 259 & 5.4 & 87 & 24.2 & \\
\hline Other Diagnosis & 3728 & 77.8 & 122 & 34.0 & \\
\hline Previous suicide attempts & & & & & $<0.001$ \\
\hline No & 4866 & 99.9 & 328 & 90.9 & \\
\hline Yes & 7 & 0.1 & 33 & 9.1 & \\
\hline
\end{tabular}

\section{Multivariate analysis}

A multivariate generalised estimating equation logistic regression model was performed, taking into account all the variables significantly associated with suicide attempts in the univariate analysis. 
Adjusting by age, gender, educational level, cohabitation status, employment status, the psychiatric diagnosis at the moment of the interview, and the information on previous suicide attempts, we found that the variables associated with the risk of making a suicide attempt were: age, psychiatric diagnosis and previous suicide attempts. The area under the ROC curve (AUC), as a measure of model validity, was 0.805 .

The risk of suicide attempt decreases with age $(\mathrm{OR}=$ 0.969), while psychiatric diagnosis was associated with a higher risk of suicide attempts: the highest risk was found for Mood or Affective Disorders (OR = 7.49), followed by Personality Disorders $(\mathrm{OR}=7.31)$, and Schizophrenia and Other Psychotic Disorders $(\mathrm{OR}=5.03)$.

The strongest single factor predictive of suicide attempt was a prior history of attempted suicide (OR = 23.63) (Table 2).

After stratifying by gender (Table 3), the variables associated with the presence of suicide attempt for both sexes were age, psychiatric diagnosis and previous suicide attempts.

The relationship between age, psychiatric diagnosis and the probability of suicide attempts according to gender in the multivariate analysis can be seen in Figures 1 and 2.

Among men, the psychiatric diagnosis with the highest risk for suicide attempts was Personality Disorders (OR $=7.18)$, followed by Affective Disorders $(\mathrm{OR}=6.18)$ and Schizophrenia and Other Psychotic Disorders (OR = 4.15).

Among women, Affective Disorders $(\mathrm{OR}=8.65)$, in the first place, followed by Personality Disorders $(\mathrm{OR}=$ 7.58) and Schizophrenia and Other Psychotic Disorders
$(\mathrm{OR}=6.38)$ were found to be associated to a higher risk of suicide attempts.

The strongest predictive factor of attempted suicide in both men and women was previous suicide attempts (Table 3).

\section{Discussion}

The present study evidences that the variables associated to suicide attempts are age, psychiatric comorbidity and previous suicide attempts. These findings are referred to in the previous literature; hence, this study, carried out on hospital patients, reflects the consistency of the results in the previously described variables [2,37-39].

The association of psychiatric illness as a predictor of suicide attempts has been reported in the literature $[9,10]$. More than $90 \%$ of patients who attempt suicide have a major psychiatric disorder [11,12], and $95 \%$ of patients who committed a suicide attempt had a psychiatric diagnosis [13]. A very recent project [40] from the World Health Organisation (WHO) produced results on the association between the diagnosis of Mental Disorders and Suicidal Behaviours in several countries (including Spain), supported by worldwide data obtained from surveys in general populations $(108,664$ people from 21 countries on five continents answered the surveys). One of its conclusions is that the presence of a psychiatric diagnosis with DMS-IV Mental Disorder criteria is a strong predictor for the appearance of suicide ideations and behaviours, as well as for consummated suicide. This applies generally to both economically developed countries and to developing countries, except for one important difference: among the Mental Disorders associated with higher suicide risk,

Table 2 Multivariate generalised estimating equation logistic regression model for predicting a suicide attempt adjusting for different variables and previous suicide attempts

\begin{tabular}{|c|c|c|c|c|c|}
\hline & Regression coefficient & Standard error & $\mathrm{p}$ & OR & $95 \% \mathrm{Cl}(\mathrm{OR})$ \\
\hline Intercept & -2.316 & 0.287 & $<0.001$ & & \\
\hline Age & -0.031 & 0.004 & $<0.001$ & 0.969 & $0.961-0.977$ \\
\hline Gender (Female) & 0.120 & 0.127 & 0.100 & 1.223 & $0.962-1.560$ \\
\hline \multicolumn{6}{|l|}{ Educational level } \\
\hline Illiterate & & & & 1 & \\
\hline Secondary education & 0.154 & 0.204 & 0.448 & 1.167 & $0.783-1.739$ \\
\hline Higher education & 0.439 & 0.257 & 0.088 & 1.552 & $0.937-2.570$ \\
\hline Living alone & 0.051 & 0.180 & 0.778 & 1.052 & $0.739-1.497$ \\
\hline Employed & 0.145 & 0.188 & 0.441 & 1.156 & $1.800-1.670$ \\
\hline \multicolumn{6}{|l|}{ Psychiatric disorders } \\
\hline Psychotic disorders & 1.615 & 0.202 & $<0.001$ & 5.030 & $3.387-7.470$ \\
\hline Affective disorders & 2.014 & 0.154 & $<0.001$ & 7.490 & $5.537-10.132$ \\
\hline Personality disorders & 1.989 & 0.169 & $<0.001$ & 7.310 & $5.249-10.180$ \\
\hline Other diagnosis & & & & 1 & \\
\hline Previous suicide attempt & 3.162 & 0.534 & $<0.001$ & 23.630 & $8.290-67.360$ \\
\hline
\end{tabular}

OR: Odds Ratio; Cl: Confidence Interval. 
Table 3 Multivariate generalised estimating equation logistic regression model for predicting a suicide attempt after stratifications according to gender

\begin{tabular}{|c|c|c|c|c|c|}
\hline Men & & & & & \\
\hline & Regression coefficient & Standard error & $p$ & OR & $95 \% \mathrm{Cl}(\mathrm{OR})$ \\
\hline Intercept & -2.737 & 0.488 & $<0.001$ & & \\
\hline Age & -0.032 & 0.006 & $<0.001$ & 0.968 & $0.956-0.980$ \\
\hline \multicolumn{6}{|l|}{ Educational level } \\
\hline Illiterate & & & & 1 & \\
\hline Secondary education & 0.702 & 0.415 & 0.091 & 2.017 & $0.894-4.551$ \\
\hline Higher education & 0.959 & 0.470 & 0.041 & 2.609 & $1.039-6.550$ \\
\hline Living alone & 0.266 & 0.235 & 0.258 & 1.304 & $0.823-2.068$ \\
\hline Employed & -0.016 & 0.288 & 0.956 & 0.984 & $0.560-1.732$ \\
\hline \multicolumn{6}{|l|}{ Psychiatric disorders } \\
\hline Psychotic disorders & 1.424 & 0.283 & $<0.001$ & 4.154 & $2.387-7.231$ \\
\hline Affective disorders & 1.822 & 0.259 & $<0.001$ & 6.182 & $3.722-10.269$ \\
\hline Personality disorders & 1.971 & 0.244 & $<0.001$ & 7.183 & $4.449-11.597$ \\
\hline Other diagnosis & & & & 1 & \\
\hline Previous suicide attempt & 3.977 & 0.659 & $<0.001$ & 53.387 & $14.662-194.388$ \\
\hline \multicolumn{6}{|l|}{ Women } \\
\hline & Regression coefficient & Standard error & $p$ & OR & $95 \% \mathrm{Cl}$ (OR) \\
\hline Intercept & -1.997 & 0.384 & $<0.001$ & & \\
\hline Age & -0.031 & 0.006 & $<0.001$ & 0.969 & $0.958-0.980$ \\
\hline \multicolumn{6}{|l|}{ Educational level } \\
\hline Illiterate & & & & 1 & \\
\hline Secondary education & -0.065 & 0.248 & 0.790 & 0.937 & $0.576-1.525$ \\
\hline Higher education & 0.250 & 0.342 & 0.460 & 1.285 & $0.657-2.512$ \\
\hline Living alone & -0.203 & 0.285 & 0.480 & 0.817 & $0.467-1.428$ \\
\hline Unemployed & 0.301 & 0.252 & 0.230 & 1.351 & $0.825-2.213$ \\
\hline \multicolumn{6}{|l|}{ Psychiatric disorders } \\
\hline Psychotic disorders & 1.854 & 0.286 & $<0.001$ & 6.385 & $3.645-11.184$ \\
\hline Affective disorders & 2.157 & 0.200 & $<0.001$ & 8.648 & $5.858-12.769$ \\
\hline Personality disorders & 2.026 & 0.240 & $<0.001$ & 7.582 & $4.738-12.133$ \\
\hline Other diagnosis & & & & 1 & \\
\hline Previous suicide attempt & 2.830 & 0.656 & $<0.001$ & 16.947 & $4.684-61.313$ \\
\hline
\end{tabular}

OR: Odds Ratio; Cl: Confidence Interval.

Affective Disorders stand out in developed countries, while the association is higher with diagnoses other than Affective Disorders, such as Impulse-Control Disorders, Substance Use Disorders and Post-Traumatic Stress Disorders, in developing countries.

In a large sample of patients in Sweden [10], the authors concluded that the category of psychiatric diagnosis coexisting with a suicide attempt is a variable which influences the future risk of consummated suicide. Planned reduction of the risk of future suicide among those patients requires implementing care plans, mainly in the first two years following the current suicide attempt, in particular among those patients diagnosed with Unipolar and Bipolar Affective Disorder, and Schizophrenia.

Although the risk of suicide increases with age, it has been demonstrated that in young adults, suicide attempts are more frequent than in older adults $[19,20]$.
These findings, in relation with age, are consistent with those of the present study. In a study of 10,892 suicides and 57,439 attempted suicides among hospital-admitted individuals in 8 states, groups with high attempted suicide rates were teenagers, young adults, women, and people of Caucasian and Afro-American origin aged 25 to 44 years [19]. Another study in Korea with 344 attempted suicides found that a significantly higher number of women than men were admitted to emergency rooms due to attempted suicide during the study period [21]. In a random sample of 3021 adolescents aged 14-24 years, the females who attempted suicide showed suicidal thoughts and suicide attempts significantly more often, and suicide attempts at a far younger age than the males [23].

A systematic review of studies on the epidemiology of suicide published from 1997 to 2007 showed that non- 




Figure 1 Relationship between probability of suicide attempt, age and grouped diagnosis in women.

fatal suicidal behaviours are more prevalent among women and young, unemployed, unmarried individuals, with low levels of education and suffering from a psychiatric disorder [1]. Our results are consistent in relation with age, gender and psychiatric disorders, but they do not coincide with the aforementioned study with regard to the variables of educational level and unemployment. In the univariate analysis we found a higher rate of suicide attempts among working populations, and with higher educational levels. The utilisation of health care services is probably related to socioeconomic status and educational level. Nonetheless, owing to the fact that we only have information on those patients who finally went to the hospital, we cannot make inferences regarding this point. In the multivariate generalised estimating equation logistic regression analysis, the association with educational level and employment disappears.

The variable most strongly associated with suicide attempts in the study is that of a prior history of

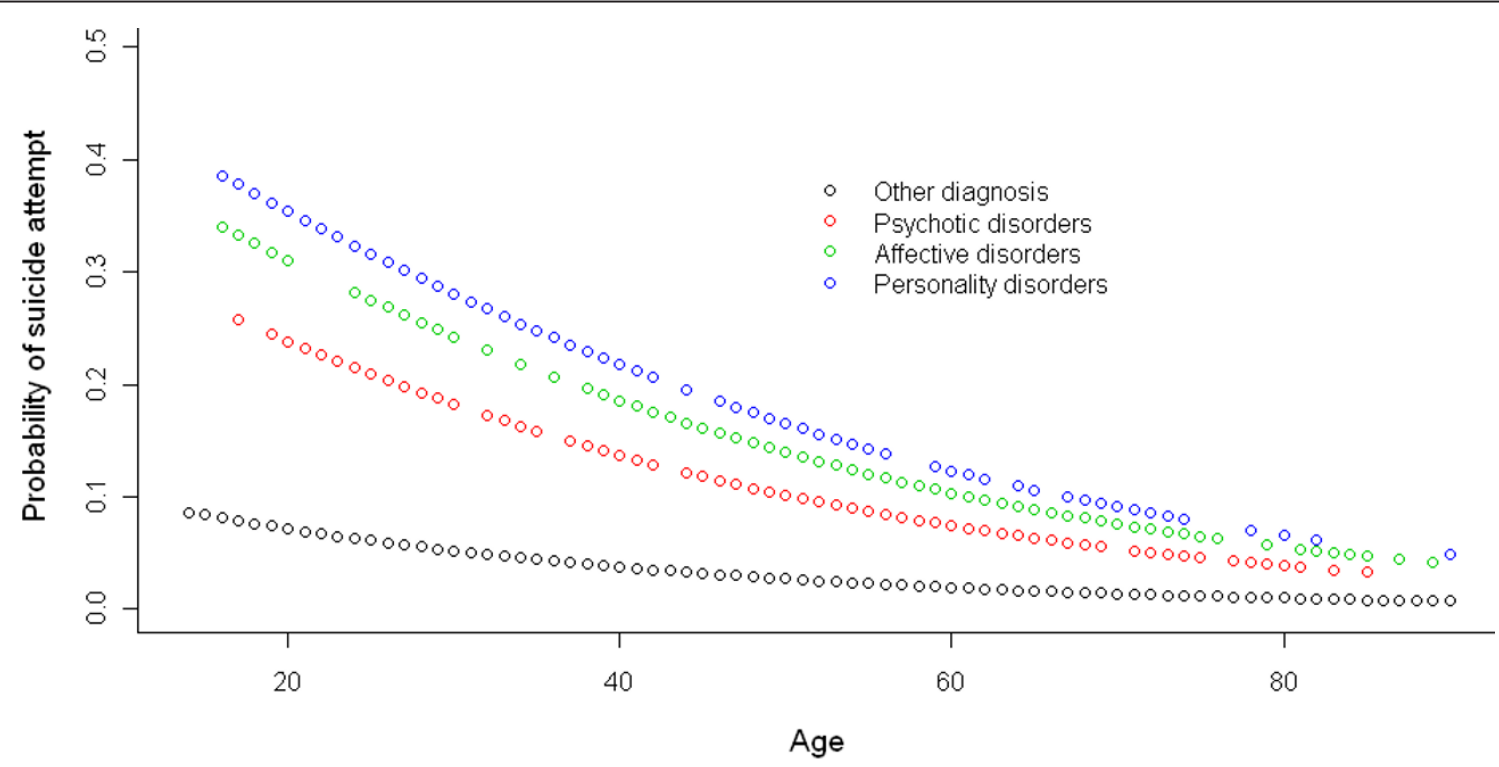

Figure 2 Relationship between probability of suicide attempt, age and grouped diagnosis in men. 
attempted suicide. Ecological studies showed a positive correlation between rates of attempted suicide and suicide rates for both sexes among young people in Europe [41]. Prospective monitoring studies of patients hospitalised as a result of a suicide attempt show that the risk of suicide and all causes of mortality were very high immediately after discharge [9]. In a systematic review of data published on the following-up of patients subsequent to failed suicide attempts [42], the authors found that, in a one-year follow-up period subsequent to the failed suicide attempt, the repeat attempt rate was $15 \%$. There is a strong correlation between suicide attempt and subsequent death by suicide. In a study of a group of patients who attended the General Hospital after a self-harm episode, the presence of previous self-harm episodes is a risk factor for the onset of future suicidal behaviours [6]. This implies that outpatient care after attempted suicide is of paramount importance. Despite this fact, the identification of specific individuals who will go on to attempt and consummate suicide is currently unfeasible, owing to the scant sensitivity and specificity of the identification procedures available, and the low base rate of this behaviour $[17,18]$.

Similar findings with respect to age, sex and previous suicide attempts have been reported in other publications. Thus, a study on a European level shows how the person-based suicide attempt rates were higher among women than among men and the highest person-based rates were found in the younger age groups [37]. Moreover, more than $50 \%$ of the individuals attempting suicide made more than one attempt [37]. Another study shows connection between suicide attempts and the individuals in the youngest age group, who reported suicidal ideation at baseline and psychiatric disorders, especially depression and drug abuse [38]. A systematic sample of 114 patients from consecutive cases of attempted suicide referred to a general hospital in Helsinki shows that a high proportion of individuals attempting suicide (82\%) suffered from comorbid mental disorders [39].

In turn, in a population-based study conducted in Spain [2] among young women, mental disorders and psychiatric comorbidity and recent ideation of suicide were identified as high risk factors for an attempted suicide. Episodes of severe depression are the diagnosis representing the greatest risk in relation to the presence of the ideation of suicide and attempted suicide.

In relation with the differences found between men and women, the literature shows that a history of suicide attempt is significantly associated with any anxiety, personality, or substance use disorder among both men and women. However, in men, suicide attempts had a strong association with dependent personality disorder (adjusted odds ratio $=3.81 ; 95 \% \mathrm{CI}=1.14$ to 12.73 ), whereas in women, suicide attempts had a strong association with antisocial personality disorder (adjusted odds ratio $=2.71 ; 95 \% \mathrm{CI}=1.72$ to 4.25 ) [43].

\section{Limitations of the study}

The present study has a number of shortcomings and biases, which we will now go on to point out. Attempted suicide is more difficult to study than consummated suicide, as there is a lack of generally approved reporting procedures for the former [44]. The possibility of a certain degree of under-reporting of attempted suicide in the present study cannot be excluded.

Another selection bias is associated with the use of hospital patients as a comparison group for identifying risk factors associated with suicide attempts.

The study is clearly conducted on admitted patients, some of whom are admitted owing to attempted suicide and others who are not (comparison group). Thus, the inference is not intended to be the general population, rather the sub-set of patients who are admitted to hospital. Nonetheless, given the magnitude of the problem in this sub-set of patients, we feel that it is relevant to be able to define the variables associated with the attempted suicide, while clearly accepting that these are patients who have been admitted for medical-surgical problems.

Given that the controls used in the hospital study are patients who also suffer from psychiatric disorders, we are aware of the presence of Berkson's bias $[45,46]$, which occurs when hospital controls are used as a reference group. If the controls are hospitalised due to an exposure that is also related to the disease under study, then the measure of effect may be weakened; i.e. biased towards the null hypothesis of no association. This produces a systematically higher exposure rate among the comparison group, an therefore distorts the odds ratio with an underestimation of the suicide attempt risk. In this sense, we can confirm that the odds ratios associated with the mental disorder in the present study are lower than those that could be obtained in a population-base study. This has been confirmed by comparing the results of the present study with the populationbased study by Gabilondo et al. (2007) [2], which shows how the presence of mental disorders is associated with a significant increase in attempted suicides, with higher odds ratio values than found in the present study, pointing towards an underestimation of the risk of attempted suicide depending on the type of controls used, as could have been expected.

Despite the underestimation of this effect, our findings are consistent with those from other studies and metaanalyses which show how psychiatric illness is a strong predictor of suicide $[9,10,47]$. A psychiatric disorder has 
also been identified as the strongest risk factor for attempted suicide [48-51]. More than 90 percent of patients who attempt suicide have a major psychiatric disorder [11,12]. Among patients with depression, a history of suicide attempts correlated most strongly with feelings of worthlessness [43]. Concurrent personality disorder was also strongly correlated with suicide attempts in depressed patients [43].

In relation to previous suicide attempts, we consider that one explanation for the extremely high association of previous suicide attempts with a current suicide attempt in this study could be that after the initial attempt, individuals may tend to stay with their family, being referred to the hospital more often after a subsequent suicide attempt. There may be an association between attending hospital after a suicide attempt and repeated suicide attempts. This effect, which is described as surveillance bias or detection bias, occurs when one group is monitored more closely than the other group, and it may lead to an outcome being diagnosed more often in the more closely monitored group, but not because it actually occurred more frequently in that group. This association with previous suicide attempts was also identified in a nationwide study in Finland [9], and in a prospective study [17] in which the authors found that the strongest single factor for suicide is prior history of attempt suicide.

There may also be an information bias due to the fact that the diagnoses of mental disorders were not based on standardised diagnostic interview schedules, but instead were clinical diagnoses made by the psychiatrists treating the patients.

As a number of patients were admitted on multiple occasions, the results may be affected by the lack of independence among admissions. The analysis was conducted with hospitalisation as the unit of analysis, including 5,234 admissions from 4,509 patients. As previously mentioned, this means that 725 (16.1\%) were readmissions, some concerning the same patients. To overcome this problem, the statistical analysis was performed using generalised estimating equations, in order to take into account the correlated nature of the data. More specifically, multivariate generalised estimating equation logistic regression models were used to identify those variables associated with suicide attempts [35]. This analysis takes into account the fact that the same patient could be admitted more than once during the study period. Generalised estimating equations are an extension of the generalised linear model, which takes into account this within-group correlation. They assume that the dependent variable of analyses can be expressed as a linear function of the independent variables through a monotonic differentiable link function, and that the variance of the dependent variable is a known function of its expectation. The parameters of the model are then estimated subsequent to the specification of the intracluster dependency correlation matrix.

In conclusion, our results show that the variables related to suicide attempt are age, psychiatric disorders and previous suicide attempts. This study in a hospital setting shows similar findings to population-based studies. Even though there is limited evidence as to the accuracy of screening tools for identifying suicide risk in the primary care setting, including tools for identifying those at high risk [52], physicians should remain alert to the possibility of suicide in high-risk patients, particularly if there is evidence of psychiatric disorder or if the patient has recently attempted suicide.

\section{Conclusions}

The variables associated with suicide attempt are age, previous suicide attempts and certain grouped psychiatric diagnosis (Schizophrenia and Other Psychotic Disorders, Affective Disorders and Personality Disorders).

The risk of suicide attempts decreases with age. Psychiatric illness is a strong predictor of suicide attempt. The strongest single factor predictive of suicide attempts is a prior history of attempted suicide.

This study in a hospital setting shows similar findings to population based studies.

Even though there is limited evidence as to the accuracy of screening tools for identifying suicide risk in the primary care setting, including tools for identifying those at high risk, physicians should remain alert to the possibility of suicide in high-risk patients, particularly if there is evidence of psychiatric disorder or if the patient has recently attempted suicide

\section{Author details}

${ }^{1}$ Department of Psychiatry, A Coruña Hospital, UPIE Planta Baja, Hospital de Oza, As Xubias, 84, 15006 A Coruña, Spain. ${ }^{2}$ Clinical Epidemiology and Biostatistics Unit, A Coruña Hospital, As Xubias, 84, 15006 A Coruña, Spain.

\section{Authors' contributions}

JAS and SGP conceived the study and participated in its design. FIGB, JGF, GMS and SLL collaborated in the design of the study and data collection. SPF and SPD participated in the design of the study and performed the statistical analysis. JAS, SPF and SPD drafted the manuscript. All authors read and approved the final manuscript.

\section{Competing interests}

The authors declare that they have no competing interests.

Received: 24 August 2010 Accepted: 31 March 2011

Published: 31 March 2011

\section{References}

1. Nock M, Borges G, Bromet E, Cha C, Kessler R, Lee S: Suicide and suicidal behavior. Epidemiol Rev 2008, 30:133-154.

2. Gabilondo A, Alonso J, Pinto-Meza A, Vilagut G, Fernández A, SerranoBlanco A, Almansa J, Codony M, Haro J: [Prevalence and risk factors for suicide ideation, plans and attempts in the Spanish general population. Results from the ESEMeD study]. Med Clin (Barc) 2007, 129(13):494-500. 
3. Hawton K, van Heeringen K: Suicide. Lancet 2009, 373(9672):1372-1381. 4. Tejedor Azpeitia M, Díaz Pérez A, Álvarez Martínez E, Castillón Zazurca J, Pericay Hosta J: Intento de suicidio: cambios epidemiológicos entre 1969-1996. Estudio retrospectivo de 1.150 casos.;[Attempted suicide: epidemiological changes between 1969-1996. A retrospective study of 1,150 cases]. Actas Esp Psiquiatr 1999, 27(5):292.

5. Ruiz-Pérez I: El suicidio en la España de hoy. Gaceta Sanitaria 2006, 20(Supl 1):25.

6. Harriss L, Hawton K, Zahl D: Value of measuring suicidal intent in the assessment of people attending hospital following self-poisoning or selfinjury. Br J Psychiatry 2005, 186:60-66.

7. Skegg K: Self-harm. Lancet 2005, 366(9495):1471-1483.

8. Schreiber J, Culpepper L, Fife A: Suicidal ideation and behavior in adults. In UpToDate Edited by: Solomon D 2010.

9. Haukka J, Suominen K, Partonen T, Lönnqvist J: Determinants and outcomes of serious attempted suicide: a nationwide study in Finland, 1996-2003. Am J Epidemiol 2008, 167(10):1155-1163.

10. Tidemalm $D$, Långström $N$, Lichtenstein $P$, Runeson B: Risk of suicide after suicide attempt according to coexisting psychiatric disorder: Swedish cohort study with long term follow-up. BMJ 2008, 337:a2205.

11. Moscicki E: Epidemiology of suicide. In Suicide prevention and intervention: summary of a workshop. Edited by: Goldsmith S. Health IoMBoNaB: National Academy Press; 2001.

12. Hirschfeld RM, Russell JM: Assessment and treatment of suicidal patients. N Engl J Med 1997, 337(13):910-915.

13. Litman R: Suicides: What Do They Have in Mind? Suicide: understanding and responding: Harvard Medical School perspectives 1989, 143.

14. Evenson RC, Wood JB, Nuttall EA, Cho DW: Suicide rates among public mental health patients. Acta Psychiatr Scand 1982, 66(3):254-264.

15. Beck AT, Steer RA, Beck JS, Newman CF: Hopelessness, depression, suicidal ideation, and clinical diagnosis of depression. Suicide Life Threat Behav 1993, 23(2):139-145.

16. Dieserud G, Røysamb E, Ekeberg O, Kraft P: Toward an integrative model of suicide attempt: a cognitive psychological approach. Suicide Life Threat Behav 2001, 31(2):153-168.

17. Pokorny AD: Prediction of suicide in psychiatric patients. Report of a prospective study. Arch Gen Psychiatry 1983, 40(3):249-257.

18. Pokorny AD: Suicide prediction revisited. Suicide Life Threat Behav 1993, 23(1):1-10

19. Spicer RS, Miller TR: Suicide acts in 8 states: incidence and case fatality rates by demographics and method. Am J Public Health 2000, 90(12):1885-1891.

20. O'Connell H, Chin AV, Cunningham C, Lawlor BA: Recent developments: suicide in older people. BMJ 2004, 329(7471):895-899.

21. Hur JW, Lee BH, Lee SW, Shim SH, Han SW, Kim YK: Gender differences in suicidal behavior in Korea. Psychiatry Investig 2008, 5(1):28-35.

22. Kumar CT, Mohan R, Ranjith G, Chandrasekaran R: Characteristics of high intent suicide attempters admitted to a general hospital. J Affect Disord 2006, 91(1):77-81.

23. Wunderlich U, Bronisch T, Wittchen HU, Carter R: Gender differences in adolescents and young adults with suicidal behaviour. Acta Psychiatr Scand 2001, 104(5):332-339.

24. Joe S, Baser RE, Breeden G, Neighbors HW, Jackson JS: Prevalence of and risk factors for lifetime suicide attempts among blacks in the United States. JAMA 2006, 296(17):2112-2123.

25. Monk M: Epidemiology of suicide. Epidemiol Rev 1987, 9:51-69.

26. Heikkinen ME, Isometsä ET, Marttunen MJ, Aro HM, Lönnqvist JK: Social factors in suicide. Br J Psychiatry 1995, 167(6):747-753.

27. Stack S: Suicide: a 15 -year review of the sociological literature. Part I: cultural and economic factors. Suicide Life Threat Behav 2000, 30(2):145-162.

28. Juurlink DN, Herrmann N, Szalai JP, Kopp A, Redelmeier DA: Medical illness and the risk of suicide in the elderly. Arch Intern Med 2004, 164(11):1179-1184.

29. Mukamal KJ, Rimm EB, Kawachi I, O'Reilly EJ, Calle EE, Miller M: Body mass index and risk of suicide among one million US adults. Epidemiology 2010, 21(1):82-86.

30. Dube SR, Anda RF, Felitti VJ, Chapman DP, Williamson DF, Giles WH: Childhood abuse, household dysfunction, and the risk of attempted suicide throughout the life span: findings from the Adverse Childhood Experiences Study. JAMA 2001, 286(24):3089-3096.
31. Qin $P$, Agerbo $E$, Mortensen PB: Suicide risk in relation to family history of completed suicide and psychiatric disorders: a nested case-control study based on longitudinal registers. Lancet 2002, 360(9340):1126-1130.

32. Agerbo E: Risk of suicide and spouse's psychiatric illness or suicide: nested case-control study. BMJ 2003, 327(7422):1025-1026.

33. Helmkamp JC: Occupation and suicide among males in the US Armed Forces. Ann Epidemiol 1996, 6(1):83-88.

34. DeJong T, Overholser J, Stockmeier C: Apples to oranges?: a direct comparison between suicide attempters and suicide completers. J Affect Disord 2010, 124(1-2):90-97.

35. Burton $P$, Gurrin $L$, Sly P: Extending the simple linear regression model to account for correlated responses: an introduction to generalized estimating equations and multi-level mixed modelling. Stat Med 1998, 17(11):1261-1291.

36. Halekoh U, Højsgaard S, Yan J: The R package geepack for generalized estimating equations. Journal of Statistical Software 2006, 15(2):1-11.

37. Schmidtke A, Bille-Brahe U, Deleo D, Kerkhof A, Bjerke T, Crepet $P$, Haring C, Hawton K, Lönnqvist J, Michel K, et al: Attempted suicide in Europe: rates, trends and sociodemographic characteristics of suicide attempters during the period 1989-1992. Results of the WHO/EURO Multicentre Study on Parasuicide. Acta Psychiatr Scand 1996, 93(5):327-338.

38. Kuo WH, Gallo JJ, Tien AY: Incidence of suicide ideation and attempts in adults: the 13-year follow-up of a community sample in Baltimore, Maryland. Psychol Med 2001, 31(7):1181-1191.

39. Suominen K, Henriksson M, Suokas J, Isometsä E, Ostamo A, Lönnqvist J: Mental disorders and comorbidity in attempted suicide. Acta Psychiatr Scand 1996, 94(4):234-240.

40. Nock M, Hwang I, Sampson N, Kessler R, Angermeyer M, Beautrais A, Borges G, Bromet E, Bruffaerts R, de Girolamo G, et al: Cross-national analysis of the associations among mental disorders and suicidal behavior: findings from the WHO World Mental Health Surveys. PLOS Med 2009, 6(8):e1000123.

41. Hawton K, Arensman E, Wasserman D, Hultén A, Bille-Brahe U, Bjerke T, Crepet P, Deisenhammer E, Kerkhof A, De Leo D, et al: Relation between attempted suicide and suicide rates among young people in Europe. $J$ Epidemiol Community Health 1998, 52(3):191-194.

42. Owens D, Horrocks J, House A: Fatal and non-fatal repetition of self-harm. Systematic review. Br J Psychiatry 2002, 181:193-199.

43. Bolton JM, Belik SL, Enns MW, Cox BJ, Sareen J: Exploring the correlates of suicide attempts among individuals with major depressive disorder: findings from the national epidemiologic survey on alcohol and related conditions. J Clin Psychiatry 2008, 69(7):1139-1149.

44. Alaghehbandan R, Gates KD, MacDonald D: Suicide attempts and associated factors in Newfoundland and Labrador, 1998-2000. Can J Psychiatry 2005, 50(12):762-768.

45. Berkson J: Limitations of the application of fourfold table analysis to hospital data. Biometrics 1946, 2(3):47-53.

46. Regeer EJ, Krabbendam L, De Graaf R, Have MT, Nolen WA, Van Os J: Berkson's bias and the mood dimensions of bipolar disorder. Int $\mathrm{J}$ Methods Psychiatr Res 2009, 18(4):279-286.

47. Bostwick JM, Pankratz VS: Affective disorders and suicide risk: a reexamination. Am J Psychiatry 2000, 157(12):1925-1932.

48. Beautrais AL, Joyce PR, Mulder RT, Fergusson DM, Deavoll BJ, Nightingale SK: Prevalence and comorbidity of mental disorders in persons making serious suicide attempts: a case-control study. Am J Psychiatry 1996, 153(8):1009-1014

49. Brent DA, Perper JA, Goldstein CE, Kolko DJ, Allan MJ, Allman CJ, Zelenak JP: Risk factors for adolescent suicide. A comparison of adolescent suicide victims with suicidal inpatients. Arch Gen Psychiatry 1988, 45(6):581-588.

50. Mościcki EK, O'Carroll P, Rae DS, Locke BZ, Roy A, Regier DA: Suicide attempts in the Epidemiologic Catchment Area Study. Yale J Biol Med 1988, 61(3):259-268.

51. Andrews JA, Lewinsohn PM: Suicidal attempts among older adolescents: prevalence and co-occurrence with psychiatric disorders. J Am Acad Child Adolesc Psychiatry 1992, 31(4):655-662

52. Gaynes BN, West SL, Ford CA, Frame P, Klein J, Lohr KN, Force USPST: Screening for suicide risk in adults: a summary of the evidence for the U.S. Preventive Services Task Force. Ann Intern Med 2004, 140(10):822-835 


\section{Pre-publication history}

The pre-publication history for this paper can be accessed here:

http://www.biomedcentral.com/1471-244X/11/51/prepub

doi:10.1186/1471-244X-11-51

Cite this article as: Alberdi-Sudupe et al: Suicide attempts and related

factors in patients admitted to a general hospital: a ten-year cross-

sectional study (1997-2007). BMC Psychiatry 2011 11:51.

Submit your next manuscript to BioMed Central and take full advantage of:

- Convenient online submission

- Thorough peer review

- No space constraints or color figure charges

- Immediate publication on acceptance

- Inclusion in PubMed, CAS, Scopus and Google Scholar

- Research which is freely available for redistribution

Submit your manuscript at 